3

\title{
Morphological Reading Errors in a German Case of Deep Dyslexia
}

\author{
Ria De Bleser and Josff Bayer
}

The case presented in this chapter is used to compare agrammatisms in speech and reading. The criteria for the diagnosis of deep dyslexia are also explored and the examination procedure for establishing the location of the functional disorder is described. The main interest of the case, however, lies in the analysis of the morphological reading errors and in the determination of their linguistic and psycholinguistic status. These areas are covered in depth.

\section{Agrammatisms in Speech and Reading}

The patient, H.J., a seamstress from a small town around Aachen, had had a cesarean section at the birth of her son when she was 22 years old. During delivery she suffered from a lung and brain embolism, which led to a relatively large perisylvian left hemisphere lesion with right hemiparesis and aphasia. In June 1978, which was 3 years after onset, she came to the RWTH hospital in Aachen for examination because of aphasia. The patient was diagnosed as a Broca's aphasic with agrammatic speech production, and she was subsequently given intensive speech therapy. During this 7-year therapy period the main improvement was in her spontaneous speech. At the time of the examination for dyslexia in 1985, agrammatic symptoms in her spontaneous speech were hardly noticeable.

Agrammatism is traditionally characterized by the lack of function words and inflected forms in specch production. The patient H.J. occasionally fit this characterization, but she also produced incorrect inflected forms. Her spontaneous speech was characterized mainly by the rare presence of complex sentence structures, which, for example, led to the frequent use of direct speech where indirect speech would have been more appropriate. In addition, she had noticeable word-finding difficulties. The following is a typical example of the patient's spontaneous speech.

Frage: Will Ihr Sohn abends nicht ins Bett?

Reaktion: Nee, freiwillig, nee ich bin nicht müde, aber jetzt habe ich gesagt, du 
mußt im Bett, du mußt morgen Schule. Wochenende darf er dann länger aufbleiben, aber so, das geht ja nicht, die halbe Nacht.

Question: Doesn't your son want to go to bed at night?

Reaction: No, volontarily, no. I am not tired, but now I said, you have to go to bed [case error], you have to go school tomorrow, weekend he can stay up longer, but this way, it doesn't work, half the night.

Frage: Wer kam auf die ldee, einen Hund zu kaufen?

Reaktion: Also erst Tino [der Sohn]. Ich hab gesagt, hier vorm Herzen da hab ich gesagt, wenn alles vorbei ist, dann kaufen wir einen Hund, ja, und dann, Operation gut überstanden und da fing er, wann krieg ich ihn denn, ja und da konnt' ich auch nicht so, nee, sag ich, zuerst müsse wir warten, ja und dann, mein Mann sagte auch ich möchte gern nen Hund.

Question: Whose idea was it to buy a dog?

Reaction: Oh, first [the name of the son]. I said, here before my heart [means: heart attack], there I said, when everything is over, then we'll buy a dog, yes, and then, operation succeeded, then he started, when will I get it then, yes and there I couldn't very well either, no, I said, first we have to wait, yes and then, my husband also said, I would like to have a dog.

The mildly agrammatic features of this conversation sample stand in strong contrast to the pronounced agrammatisms produced in reading.

"Mir wird schlecht": Mir ... schlecht

Me becomes bad Me ... bad (I'm getting ill)

"Er schrie er sei blind": Er schreien er blind

He shouted he were blind He shout he blind

"Wir liebten diese Rose": Lieben .. Rose

We loved this rose Love rose

"Du mußt ihm den Stuhl verkaufen": Du .. Stuhl verkaufen

You must him the chair sell You chair sell

The reason for this discrepancy, as we will show. is the peculiar reading disorder of the patient.

During H.J.'s aphasia therapy, semantic paralexias were occasionally noted, e.g., Kaiser (emperor) for König (king) or Vogel (bird) for Adler (eagle). This finding motivated a further examination for deep dyslexia.

\section{Assessment of Deep Dyslexia}

Apart from typical semantic paralexias, the following symptoms are also characteristic for deep dyslexia (Patterson, 1981).

1. Deep dyslexics are unable to read nonwords. 
2. "Semantic" features, such as degree of abstractness, play an important role when reading words; concrete nouns are read correctly more often than abstract ones.

3. The word category of the stimuli influences the reading performance. Content words are generally read correctly more often than function words, and there is a severity hierarchy within the group of content words; nouns are read correctly more frequently than adjectives and adjectives more frequently than verbs.

4. The frequency with which morphological errors occur depends on the structure of the stimulus word: Simple morphemes without inflectional or derivational affixes provoke relatively few morphological errors, whereas they may constitute up to $50 \%$ of the reactions for words with affixes (Patterson, 1980).

For the assessment of deep dyslexia, the patient was requested to read 80 nouns, e.g., Kunst (art), and 20 noun-like nonwords with German phonotactics, e.g., Funst (ort). The nouns were subdivided into 40 concrete nouns, e.g., Beil (axe), and 40 abstract words, e.g., Norm (norm). In addition, 60 minimal pairs of content words and function words were presented, e.g., Sieb (sieve) versus Sie (she). The percentage of correct responses is listed below:

Words $(\mathbf{n}=80)$ .635

Concrete Nouns $(\mathrm{n}=40) .875$

Content Words $(\mathrm{n}=60) \quad .87$ \begin{tabular}{ll} 
Nonwords $(\mathrm{n}=20)$ & 0 \\
Abstract Nouns $(\mathrm{n}=40)$ & .375 \\
Function Words & $(\mathrm{n}=60)$ \\
\hline
\end{tabular}

The percentage of semantic paralexias to the total amount of errors was remarkably high, even for deep dyslexics.

$\begin{array}{llll}\text { Words }(n=80) & .53 & \text { Nonwords }(n=20) & 0 \\ \text { Concrete Nouns }(n=40) & 1.00 & \text { Abstract Nouns }(n=40) & .44 \\ \text { Content Words }(n=60) & .68 & \text { Function Words }(n=60) .47\end{array}$

According to the cardinal symptoms given by Patterson (1981), this patient clearly suffered from deep dyslexia.

We then examined the influence of word category, which is said to constitute a severity hierarchy in patients with deep dyslexia (nouns $>$ adjectives $>$ verbs $>$ function words, wherein " $>$ " is defined as "more correct responses than"). The patient was requested to read underived and uninflected word forms. The percentage of correct reactions to the various word categories was as follows.

\footnotetext{
1 The category "semantic paralexias to function words" includes substitutions of one function word by another, e.g., mir (me dative $)$ for mein $\left(m_{\text {possesive }}\right)$, du $\left(y_{0 u}\right.$ nominative $)$ for $\operatorname{dir}($ you diative $)$.
} 
Nouns $(\mathrm{n}=55) \quad .74$

Adjectives $(\mathrm{n}=72) \quad .50$

Infinitive Verbs $(n=91) .47$

Function Words $(\mathrm{n}=80) .36$

Prepositions $(\mathrm{n}=28) \quad .57$

Conjunctions $(\mathrm{n}=12) .33$

Pronouns $(\mathrm{n}=24) \quad .29$

Modal Verbs $(\mathrm{n}=16) .13$

The proportion of semantic paralexias to the total incorrect responses was again high, but the percentage varied across the various types of content words.

$\begin{array}{lr}\text { Nouns } & .79 \\ \text { Adjectives } & .44 \\ \text { Infinitive Verbs } & .33\end{array}$

Following are some examples of semantic reactions.

Stimulus
Nouns
Beil (axe)
Grund (ground)
Eisen (iron)
Fürst (sovereign)
Menge (mass)
Herd (stove)
Dunst (vapor)
Adjectives
tapfer (courageous)
düster (dark)
trübe (overcast)
ledig (single)
sanft (soft)
gering (few)
Verbs
retten (save)
kosten (cost)
läuten (ring)
rennen (race)
saufen (drink a lot)
stechen (stick)
sinken (sink)

\section{Reaction}

Hammer (hammer)

Boden (floor)

Stahl (steel)

Prinz (prince)

Gruppe (group)

Ofen (oven)

Qualm (smoke)

mutig (courageous)

dunkel (dark)

das wetter, bewölkt (the weather, cloudy)

nicht verheiratet (not married)

zärtlich (tender)

wenige (few)

helfen (help)

zahlen (pay)

klingeln (ring)

laufen (run)

trinken (drink)

Messer irgendwas, schneiden (knife something, cut)

kentern $(\operatorname{sink})$

The word category effect was nevertheless not as pronounced as might have been expected according to the predictions in the English literature. 
There was no big difference between adjectives and verbs, whereas there was a lot of variance within the category of function words. For example, prepositions were read better than the infinitive of verbs, and modal verbs were much more severely affected than main verbs.

One factor that may help to explain these different results for function words could be referential content, which is much stronger in prepositions than, for instance, in conjunctions. The word category effect could thus be related to the concreteness effect. It is important to note that the disorder cannot be explained by a general impairment of phonological access, but that it is restricted to processing written material. H.J. could easily repeat every function word spoken to her.

The results for verbs and adjectives may be related to the fact that in German few adjectives are underived. We therefore had to include low frequency words in our corpus of underived adjectives. It is well known that frequency plays a role in the reading of deep dyslexics.

Strikingly, only a small portion of the responses to our word category corpus could be considered morphological errors (nouns: 1\% morphological versus $18 \%$ semantic; adjectives: $3 \%$ morphological versus $22 \%$ semantic: verbs: $15 \%$ morphological versus $18 \%$ semantic). In this corpus, only underived and uninflected word forms were presented. Therefore the relatively small number of morphological errors corresponds to the observation made by Patterson (1980) that morphological errors are most frequent in morphologically complex words. The higher amount of morphological errors in the responses to infinitival verbs may be related to the fact that the infinitive is already a morphologically complex form itself. This subject is discussed in greater detail later in the chapter.

\section{Assessment of the Functional Locus of the Disorder}

First, a paradigm of lexical decision was used, whereby the patient is requested to decide if a written or spoken letter or sound chain is a word. The stimulus material consisted of chains of four syllables, constructed in the following manner.

1. EK: existing compounds consisting of two content morphemes and a (variable) number of grammatical morphemes, e.g., Kugelschreiber (ballpoint). Schlagersänger (hit singer).

2. PA: nonwords constructed by substituting the initial phonemes of the composite parts of the compound words, e.g.. Wugelkreiber.

3. PE: nonwords constructed by substituting the final phoneme of the composite parts of the compound words, e.g.. Schlagessängel.

4. SPK: nonexisting compounds in which the composite parts were phonemically correct and semantically meaningful, but the compounded product makes no sense. e.g., Kugelsänger. 
5. NS: nonsense words constructed after a phonemically illegitimate CVCV pattern, e.g. , Kupäwagü.

Each category contained 15 items and was offered twice. Altogether 150 items were presented to the patient in randomized order, with the request to judge their correctness. The lexical decision task was performed in auditory and written presentation.

In the auditory modality, H.J.'s results were entirely normal. When given PA, PE, and NS nonwords in written presentation, H.J. made no incorrect decisions either. For real compounds. she made 3 incorrect decisions of 30 by visual presentation. Interestingly, she rejected all semantic pseudocompounds (SPK) upon visual presentation. In some cases, she commented, "not those two together," or else she would try to construct some compositional semantics but she would finally reject the composition.

Sammlerhochzeit (collector wedding): When many get married, maybe, but no.

Geschenkskrümel (present crumb): Too few presents, but no.

Nadelfeuer (needle fire): When there are too many, but no.

Pflanzenwohnung (plants dwelling): Could exist, but never heard of it.

These results indicate that $\mathrm{H} . \mathrm{J}$. could provide a rather specific semantic interpretation for an input chain upon auditory as well as graphemic presentation. Therefore her deep dyslexia does not seem to arise on the input side, between the graphemic stimulus and the semantic system, or in the semantic system itself, as the patient could even make judgments of semantic anomaly for compounds. The disturbance is more likely situated between the semantic representation and the phonological word form because, like semantics, the phonological word form itself is also undisturbed, as shown by the fact that H.J. can repeat all of the SPK pseudowords without problems, although typical reading reactions were the following.

Sammlerhochzeit (collector
wedding)
Kugelsänger (ball singer)

Kleiderbesteck (clothes cutlery)

Pflanzenwohnung (plants appartment)

Bienentabak (bees tobacco)
Sammeln-hochzeit (collect-wedding)

Bleistift irgendwas, Sänger

(pencil something, singer. (Note the semantic similarity between KugelSchreiber, or (ballpoint) and Bleistift. (pencil).

Kleider-Porzellan (clothes-porcelain)

Wohnung-Blumen nicht (appartment, flowers not)

Bienen und Zigarren-innen (bees and cigars ... in them)

The patient was further tested for reading comprehension of the classes 
of words she could hardly read aloud, i.e.. modal verbs and pronouns. It was done using a sentence/picture matching paradigm. For the modal verbs, there was a choice of only two pictures. Modal verbs are difficult to depict; and if one were to include several distractors, there would be more than one plausible target candidate. Our set included items such as (1) a boy with his leg in a cast and hung in a traction sling (target: der Junge kann nicht laufen - the boy is unable to walk), and (2) a boy who has a sour face while being pushed to move by his father (target: Der Junge will nicht laufen - the boy is unwilling to walk). Even with this restricted set, the target picture can be chosen only by comparing the two pictures and picking the one that most plausibly fits the sentence. Among the 22 sentences to be matched, the patient made five errors.

The task for reading comprehension of pronouns was more easy to develop. A group of 22 simple semantically reversible SVO sentences were constructed with a pronoun as subject and another pronoun as object, e.g., Sie sucht $i h n$-she searches him. There were two distractor pictures, one with a distractor for the subject (Er sucht $i h n-H e$ searches him) and one with a distractor for the object (Sie sucht sie-She searches her). On this task, the patient made 4 errors among 22 which is significantly above chance.

Thus the patient's poor performance regarding reading aloud modal verbs and pronouns does not stand in proportion to her rather mild disorder in grasping their meaning from graphemic presentation.

Additional data show that the route H.J. utilizes for reading proceeds as follows.

1. Segmentation of the letter chain is performed with the help of the semantic-lexical system.

2. The graphemic segments so identified are matched with an appropriate (concrete and referentially transparent) meaning.

3. The semantic content so identified is matched with a corresponding entry in the phonological lexicon.

H.J. did not segment graphemic chains by identifying the syllabic or morphemic structure as such. but only through interaction with the semantic lexical system. When reading neologisms, H.J. chose any part of the letter chain that could function as a word. For instance, when reading the stimuli of the lexical decision task described previously, she produced the following reactions.

$\begin{array}{lll}\text { Gasenläher: } & \text { Gas } & \text { (gas) } \\ \text { Säkelradel: } & \text { Rad } & \text { (bicycle) } \\ \text { Hogelpäfig: } & \text { Gel } & \text { (wet gel) } \\ \text { Mutafazö: } & \text { Mut } & \text { (courage) } \\ \text { Kauchiräpo: } & \text { Po-kau } & \text { (the behind-chew) } \\ \text { Rasiemwasset: } & \text { Was } & \text { (what) }\end{array}$


$\begin{array}{lll}\text { Probleslösunt: } & \text { Pro } & \text { (pro) } \\ \text { Binaifodü: } & \text { Bin } & \text { (am) }\end{array}$

The last three responses, where the patient picked up a function word, are comparatively rare. Usually these choices are ignored during segmentation.

Real words are segmented by H.J. under semantic guidance. When morphologically ambiguous words are offered in which both a function word and a content word can be identified (e.g., Beil-Eid versus bei-Leid, (xe-oath versus with-suffering = condolences), the composite semantics is decisive for segmentation. This situation is no different from what normal people do. "Gardenpath" words such as the following were used to examine this effect.

Her-z-eigen

her/herz, zeigen/eigen

(to/heart, show/own)

Bei-l-eid

bei/beil, leid/eid

(with/axe, suffering/oath)
Herz. zeigen, her.zeigen

heart show to show = show up

\section{Mitleid}

with suffering $=$ pity

Only in the case of low frequency words or abstract words could semantics not provide the necessary information for correct segmentation.

$\begin{array}{lcc}\text { Ab-t-rudeln } & a b t \text { (as in church) . ruder } \\ \text { ab/abt, trudeln/rudeln } & a b b o t & \text { oar } \\ \text { (off/abbot, move/packs) } & & \end{array}$

$\begin{array}{lc}\text { Zu-g-riff } & \text { Zug . } \emptyset \\ \text { zu/zug, griff/riff } & \text { train } \\ \text { (to/train, grip/reef) } & \end{array}$

As the direct phonological-lexical route is missing, H.J. proceeded with the identified graphemic segments to the cognitive system and combined them with their referential semantics. It was then often linked to the wrong phonological form, resulting in semantic paralexias. Segments without clear referential semantics cannot be realized phonologically, which explains the following.

1. Differences between proper names and common nouns. H.J. could read only 6 of 70 proper nouns; the remaining 64 produced no response. When asked to identify the sex, she made only 8 errors. Twenty of the names had been chosen because they were exceptions to the German rule that names ending on consonants are masculine, and names ending on vowels are feminine. Examples of the irregular pairs are Otto (male ending on a vowel). Gertrud (female ending in a consonant). Another 20 names 
showed no differences in form between male and female, e.g. Martin, Karin. The remaining 30 names were regular. e.g., Josef, Claudia.

For the simple common nouns in this test material, $20 \%$ of the responses were semantic paralexias, which was about $50 \%$ of the total error rate, zero reactions included. Most reactions were related to the stimulus item by coordination/synonomy. The second most frequent type of semantic paralexia were paraphrases.

2. Differences between derivational affixes. H.J. paraphrased the diminutive endings -chen and -lein with "klein" (small). Both endings were sometimes realized phonologically as -chen after such circumscription: in 8 of 15 cases of the -chen diminutives and in 6 of 15 of the -lein diminutives.

Briefchen (small letter) Brief.kleines.chen (letter small.diminutive affix)

Männlein (small men) kleiner Mann. Männchen (small man . man+ diminutive affix)

Türchen (small door) Tür.kleine. Türchen (door.small. door+ diminutive affix)

The prefix un- was also paraphrased semantically with the free morpheme nicht (not). H.J. resorted to this strategy not only to describe the transparent derivations but often also in pseudoderivations.

unmutig (displeased)

unbillig (unfair)

unwegsam (impracticable) nicht mutig (not couragous)

nicht billig (not cheap)

nicht Weg irgendwas (not way something)

The phonological form un- was not produced once in 45 cases, nicht in 15 of 30 derivations and in 7 of 15 pseudoderivations.

The suffix -bar (-able) was treated differently again. Although it can be paraphrased semantically, it cannot be done so with a single word. A paraphrase occurred only once in 30 cases: kann man mischen (one can mix it) for mischbar (mixable). However, -bar was often realized phonologically (in 13 of 30 cases). Because - bar also has a homophonous noun, which H.J. could read (e.g., Bühnenbar was read as Theater. bar). the interpretation of -bar as a suffix was unlikely at least in some of the reactions.

machbar (doable)

trinkbar (drinkable)

ergreifbar (graspable) bar aber. . keine Ahnung (bar but. . no idea)

trinken. . bar (drink . bar)

greifen. . wieder bar (grasp. . again bar)

The suffixes $i g$. -isch, and -lich can hardly be paraphrased semantically. These suffixes have the syntactic eategory of adjective and are used to derive adjectives from nouns. They were rarely realized phonologically (of 30 items each, 4 for $-i g, 0$ for $-i s c h$, and 5 for -lich). Reactions were mainly restricted to the nominal root. 


$\begin{array}{ll}\text { staubig (dusty) } & \text { Staub (dust) } \\ \text { heimisch (homy) } & \text { Heim (home) } \\ \text { mündlich (orally) } & \text { Mund (mouth) }\end{array}$

So far, the differential treatment of the above suffixes seems to be compatible with an alternative explanation to the "semantic content" hypothesis. The diminutive and negation affixes are category-preserving, whereas the adjectival suffixes -ig, -isch, and -lich have a syntactic funetion converting nouns into adjectives. The patient might have a particular inability to read syntactic affixes. To test this assumption, we presented words with other negation affixes, 10 with the adjectival -los (-less), and 10 with the verbal prefix ent- (de-), e.g., herz-los (heart-less), ent-gift-en (de-poison: to take the poison out).

The patient correctly read 3 of 10 -los items and 3 of 10 ent- items. The remaining reactions provoked semantic paraphrases, as in the case of the nonsyntactic un-:

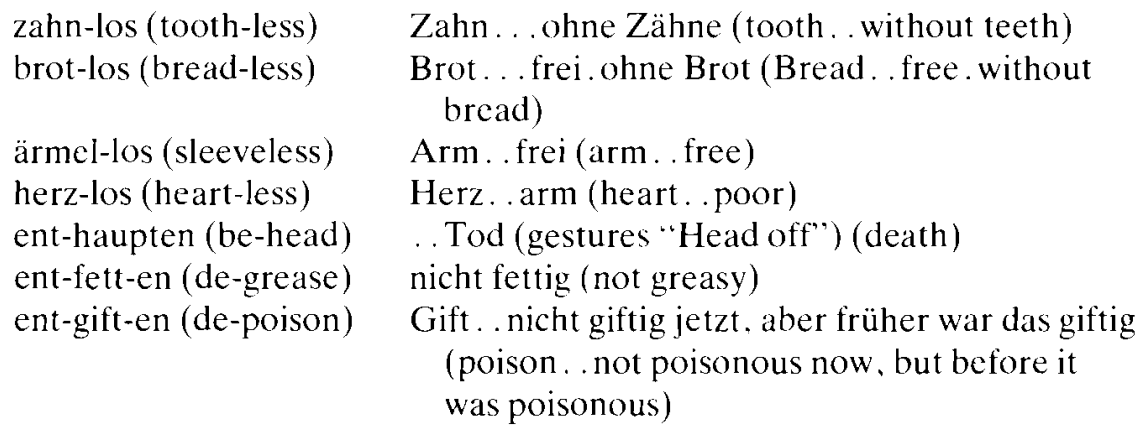

These examples indicate that semantically paraphrasable affixes were processed by the patient irrespective of their syntactic status.

\section{Morphological Reading Errors}

The morphological structure of words is richer in German than in English. This fact motivated us to take a closer look at the interaction between the internal structure of the morphological lexicon and the direct. semanticlexical route for reading.

The starting point of our own examination and of the current debate in the literature was a descriptive study by Patterson (1980) on the "derivational" errors two English-speaking deep dyslexics had produced. The term "derivational error" used by the author included both inflectional and linguistically speaking derivational morphological relations between stimulus and response. In her study of the two patients with deep dyslexia, P.W. and D.E., who like our patient were also of the output kind, Patterson concluded that the derivational paralexias collected from the reading 
TABLE 3.1. Reading of affixed words-affix responses of two English deep dyslexics.

\begin{tabular}{|c|c|c|c|c|c|c|c|c|c|c|}
\hline Jarget & -ing & -er & $-1 y$ & $-y$ & -ed & -est & -tion & Other & Deletc & $\begin{array}{c}\text { Total } \\
\text { No. }\end{array}$ \\
\hline Response & & & & & & & & & & \\
\hline -ing & .58 & .07 & - & .02 & .04 & - & .02 & .02 & .25 & 53 \\
\hline -er & .13 & .57 & .10 & - & - & - & -- & - & .20 & 30 \\
\hline -ly & .109 & .05 & .48 & - & - & - & - & - & .38 & 21 \\
\hline$-y$ & .07 & - & - & .80 & - & - & - & - & .13 & 15 \\
\hline -ed & .09 & - & - & .05 & .05 & - & .09 & .09 & .64 & 22 \\
\hline -est & $\cdots$ & .45 & - & - & - & .09 & - & - & .45 & 11 \\
\hline -tion & - & - & - & -- & - & - & .22 & .56 & .22 & 9 \\
\hline Toul & 40 & 27 & 13 & 14 & 3 & 1 & 5 & 8 & 50 & 161 \\
\hline
\end{tabular}

(C) From Patterson (1980). With permission from Routledge \& Kcgan Paul Ltd.

data revealed a systematic pattern. Seven productive suffixes were available for analysis, and all of them were frequently deleted. There were, however, differences in the correct production of the various suffixes; for example, the suffixes -ing, -er, $-l y$, and $-y$ were often read correctly, whereas -ed and -st were never produced correctly. Also, the suffixes -ing and -er were frequently used as substitutes for other suffixes (Table 3.1).

The author herself did not offer any theoretical explanation for the observation of these patterns. An attempt at a theoretical explanation for the Patterson data was later made by Futter and Bub (1986). These authors used the framework of lexicalist morphology/phonology (Kiparsky, 1982). In the next section we will evaluate their proposal.

\section{Morphological Errors and Linquistic Models}

\section{Morphological Errors and Lexical Morphology}

Lexical morphology adopts three layers in the lexicon that have different functions in word building.

Level 1 contains derivational and inflectional word formation with rootchanging affixes (e.g., decide/decision).

Level 2 contains phonologically neutral affixation processes for derivation and compounding (e.g., man/manly).

Level 3 contains regular inflectional processes.

On the basis of such a model, Futter and Bub (1986) assumed that morphological paralexias would reveal the following characteristics.

I. Simplifications, i.e., suffix deletions, would occur most frequently. 
whereby the suffixes of level I would be omitted more often than those of level 2 , and the latter, again, more often than those of level 3 .

11. In cases of suffix substitution, affixes of levels 2 and 3 would be used for those of level 1 and not the reverse (e.g., decision $\rightarrow$ deciding).

On the whole, there would exist a hierarchy of disturbance in which the $n-1$ level would always be more prone to disturbance than level n, i.e., level $1>$ level $2>$ level 3 ( $>=$ more disturbance prone).

Both assumptions can be examined in German by means of inflected verbs, which may follow a regular or irregular paradigm.

\begin{tabular}{|c|c|c|c|}
\hline $\begin{array}{l}\text { Condition } \\
\text { Infinitive }\end{array}$ & $\begin{array}{l}\text { Regular } \\
\text { spülen } \\
\text { (rinse) }\end{array}$ & $\begin{array}{l}\text { Irregular I } \\
\text { bringen } \\
\text { (bring) }\end{array}$ & $\begin{array}{l}\text { Irregular II } \\
\text { fahren } \\
\text { (drive) }\end{array}$ \\
\hline Present, 3rd person singular & $\begin{array}{l}\text { spült } \\
\text { (rinses) }\end{array}$ & $\begin{array}{l}\text { bringt } \\
\text { (brings) }\end{array}$ & $\begin{array}{l}\text { fährt } \\
\text { (drives) }\end{array}$ \\
\hline Past simple & $\begin{array}{l}\text { spülte } \\
\text { (rinsed) }\end{array}$ & $\begin{array}{l}\text { brachte } \\
\text { (brought) }\end{array}$ & $\begin{array}{l}\text { fuhr } \\
\text { (drove) }\end{array}$ \\
\hline Past participle & $\begin{array}{l}\text { gespült } \\
\text { (rinsed) }\end{array}$ & $\begin{array}{l}\text { gebracht } \\
\text { (brought) }\end{array}$ & $\begin{array}{l}\text { gefahren } \\
\text { (driven) }\end{array}$ \\
\hline Imperative & $\begin{array}{l}\text { spül } \\
\text { (rinse) }\end{array}$ & $\begin{array}{l}\text { bring } \\
\text { (bring) }\end{array}$ & $\begin{array}{l}\text { fahr } \\
\text { (drive) }\end{array}$ \\
\hline
\end{tabular}

According to $I_{\text {., }}$ the imperative form of the verb would be expected to be the most frequent default form, as it is the only existing form with possible homophony to the stem; e.g.. gehen (to go)/geh (go).

According to 11 ., one would expect a difference between regular and irregular inflection forms. Futter and Bub did not assume a general lexical disturbance in cases of deep dyslexia, i.e., no regularizations of irregular forms should occur as, for example, lief $\rightarrow{ }^{*}$ laufte (ran $\rightarrow{ }^{*}$ runned). They, rather, assumed that when a patient reads a word all morphologically related words are activated as well. Contrary to normal readers, however, the patient is unable to filter out the inadequate forms. When deciding which form to choose from the variety of candidates, he picks out the more regular form. Accordingly, quantitatively more errors would have to be expected when irregular forms are read, and irregular forms should occur less often as reactions as well.

H.J. read a total of 316 verb forms (infinitive, present, imperfect, and perfect participle-79 of each). For the infinitive, there were $16 \%$ morphological errors and for the other forms, $49 \%, 43 \%$, and $46 \%$ were morphologically ineorrect, respectively. None of these morphological errors consisted in the production of an imperative or a verbal root. The responses were restricted exclusively to infinitives, present tenses, morphologically related nouns, participles, and the past tense form. The frequency of occurrence of these forms is given as a percentage in Table 3.2. The number of items includes correct and morphologically related re- 
TAB1.F 3.2. H.J.'s responses when reading 4 different verb forms.

\begin{tabular}{|c|c|c|c|c|c|}
\hline Tinget Response & Inf. & Pres. & Imperf. & Partic. & Noun \\
\hline Inf. $(n=5(0)$ & .74 & .10 & .00 & .12 & .14 \\
\hline Pres. $(n=49)$ & .59 & .21 & .00 & .12 & .08 \\
\hline Imperf. $(n=40)$ & .50 & .18 & .15 & .02 & .15 \\
\hline Partic. $(n=49)$ & .55 & .12 & .00 & .25 & .08 \\
\hline
\end{tabular}

( $n=$ number of itcms which did not attract semantic or visual errors or zero-responses; correct responses are boxed.)

actions to a specific verb form. Those errors showing semantic or visual similarity and zero reactions are not considered here.

The system in H.J.'s reading is obvious. The patient reads approximately $20 \%$ of the target forms correctly. whereas in over $50 \%$ of the reactions the infinitive is used as a default form. This explains why in the case of infinitive forms "apparently correct" responses are so frequent.

The analysis of the patient's responses to regular and irregular imperfect tense forms provided the results shown in Table 3.3. None of the 30 regular imperfective forms was read correctly. In 11 of 30 cases the infinitive was substituted; in 2 of 30 cases a present tense was substituted; and in 5 of 30 cases the substituted form was a morphologically related noun. The remaining reactions were either visually $(n=1)$ or semantically $(n=6)$ related words or zero reactions $(n=5)$. Of the 49 irregular imperfect forms, 6 were read correctly, 9 were realized as an infinitive. 5 as present tense, 1 as a participle, and 1 as a noun. Of the remaining responses, 10 were visually related. 3 were semantically related. and there were 14 zero reactions.

These results contrast sharply with the expectations set up by Futter and Bub. If an imperfective form was read at all, it was an irregular, phonologically marked form, not a regular one.

Additional evidence concerning a difference between reactions to inflectional forms of level 1 and those of level 3 can be obtained by comparing the plural forms of nouns to the comparative and superlative forms of adjectives.

TABLE 3.3. H.J. s reading of regular and irregular imperfective forms.

\begin{tabular}{lccccccc}
\hline Response & Imperl. & Inf. & Pres. & Partic. & Noun & 0 & Other \\
\hline Imperf. reg. $(\mathrm{n}=30)$ & 0 & .36 & .07 & .00 & .17 & .17 & .23 \\
Imperf. irreg. $(\mathrm{n}=49)$ & .12 & .18 & .10 & .02 & .02 & .29 & .27 \\
\hline
\end{tabular}


With the exception of the $-s$ plural, German plural forms are largely unpredictable and must thus be localized in level 1 of the lexicon. ${ }^{2}$ In contrast, the comparative and supcrlative form of adjectives may count as regular inflection and would thus be located in level 3 of the lexicon.

The patient was offered 10 singular forms and 30 plural forms to read. The plural forms were composed as follows: $\because 2$ (Stock/Stöcke), $\because \emptyset$ (Vater/ Väter), and :or (Glas/Gläser). Of the 10 singular forms. 9 were read correctly; and in one case there was a semantic paralexia in the singular. In contrast, only 5 of the 30 plurals were rcad correctly (Züge. Hüte. Bücher, Häuser, Gärten); and in four additional cases, the first reaction was a singular noun that was then changed to a plural, whereas in two cases a paraphrase with viele (many) intervened. In 20 of 30 cases, only the singular form was provided; and in one case there was a zero reaction.

This performance was restricted exclusively to phonological output by graphemic input, however. When the patient was requested to orally pluralize singular forms (the 30 stimuli were thc same as those in the graphemic plural reading task), 27 of 30 correct plural forms were produced; in only 3 cases did a stimulus remain unchanged. The patient thus shows only minimal impairment in her ability to produce plural forms. Therefore the morphological errors produced during reading are not caused by disturbances of the morphophonological representation itself but by the ability to adequately process graphemic stimuli. Once more, it could be shown that this disorder must be on the output side of the semantic system by asking the patient to match word cards with a singular versus a plural noun (18 items each) to pictures with one or several objects. In this task, H.J. only made 1 of 36 possible errors, which means that she grasped well the plural versus the singular meaning of the graphemic input that she could not transform phonologically.

Regular inflection (level 3) applies in the case of comparative and superlative forms of adjectives. Patterson (1980) had reported that her two English patients almost never produced the superlative affix -est and that the comparative ending -er was far more likely to be produced. Our patient H.J. read 12 highly frequent monosyllabic adjectives correctly and with ease. The comparative and superlative forms of these adjectives. presented in a different session, were never read as such. Eleven of the com-

\footnotetext{
This assumption is extensively discussed for the German language by De Bleser and Bayer (1986). Neurolinguistic data are also offered there on the lexical status of the productive s-plural: Patients practically lacking syntactic abilities were still capable of productively deriving this form with their isolated morpho-phonological lexicon. The attribution of German plural forms (with the exception of $-s$ ) to level 1 of the lexicon is not contradicted by Köpcke's data (1987). Köpcke offered neologisms to native-speaking German controls to be pluralized, e.g. " das flett." The variety of reactions to the monosyllabic neologisms was remarkable. and agreement on one specific plural form ranged at best between 40 and $66 \%$. The three possible "umlaut" forms ( $\because(0, \ddot{-a}$, and "̈rr) were almost completely ignored.
} 
paratives and eight of the superlatives were read in the positive equivalent. Never did a semantic paraphrase with mehr (more) or meist (most) occur. One comparative form (älter: older) was changed to a noun (alter: age). In two cases where the target form was a superlative, the weak congruence form occurred (kleinst/kleine, blindest/blinde). In another two cases, there was incorrect segmentation so that the noun Test (test) (carrying stress unlike the suffix -est) occurred as a reaction (ältest $\rightarrow$ Test; ernstest $\rightarrow$ ernst. .Test). Twenty additional comparatives, all with the "umlaut" form, were mixed with 50 nouns ending on -er. The latter were monomorphemic nouns such as Hocker (stool) and agentive nouns such as Drucker (printer). Even in this condition, no comparative form was read. and the positive form occurred as a reaction in 16 cases. There were three semantic paralexias and one zero reaction.

A comparison of H.J.'s reactions to plural noun forms and graded adjectives shows that, as with the imperfective forms of the verbs, irregular inflections stand a slightly better chance of being read correctly than the regular forms. This finding may imply that Futter and Bub have psycholinguistically misinterpreted the hierarchy of lexical morphology. Instead of being $1>2>3$ (> expressing more prone to disorder), it is actually the opposite, $3>2>1$. This order is also more in line with the "feeding relations" postulated in such layered models, according to which, level 1 can feed into level 2, but 3 cannot (lice-infested but not * rats-infested, in other words, irregular plurals precede compounding, but regulars must follow it). For pathology, one would expect it to mean that level 2 could still function well when level 3 is disturbed but not when level 1 is impaired.

In general, however, H.J.'s correct reading of inflected forms is too rare to support or reject such assumptions. What the data clearly express is that H.J.'s morphological errors cannot simply be captured by "omission or substitution of suffixes," as is done frequently in the current literature. Nouns and adjectives are not simply stripped of their suffixes, but the citation form (singular noun, positive adjective) is used as a default form, even if it is based on a different stem (nonumlaut stem) than the inflected form. The substitution of one suffix for another did not occur at all in H.J.'s data for nouns and adjectives.

For verbs, simple suffix deletions would often have been possible, resulting in an imperative. However, H.J. did not produce imperatives. Instead, in over $50 \%$ of the cases another form, i.e., the infinitive, was substituted for the inflected form. Other less frequent default forms were the third-person present tense (over 10\% of the cases) or a morphologically related noun. A simple subdivision of suffixes in regular and irregular ones is not sufficient for the interpretation of the data, as the regular suffixes are clearly not treated equally with respect to suffix substitution processes. Even if the present tense, the past tense, and the participle are part of a regular paradigm, the imperfective form is never used for substitution and the participle only rarely so. H.J.'s data, rather, indicate 
that there are lexical marking principles at work in regular paradigms and that the infinitive is the least marked and therefore frequently occurs as a default form.

Some anecdotal data of H.J. may show the strength of this tendency toward the unmarked form. Not only did she read infinitives instead of imperatives (the "stem" forms), but she did so even at the expense of syntactic structure. In German verbs, the verbal particle precedes the infinitive, but it must, due to the verb-second rule, follow the imperative. In 4 of 10 cases, H.J. substituted the lexical citation form with particleplus-infinitive for an imperative-plus-particle.

Lies vor (read Lesen . . vorlesen (to read. . to read aloud) aloud)

Steig hinauf Steigen:..hinuntersteigen (to go...to go down) (go up)

Spring hinunter Springen... hinunterspringen (to jump... to jump (jump down) down)

Such weiter Suchen...weitersuchen (to look... to look further) (look further)

A similar pattern with transgression of syntactic structure occurred in another investigation dealing with compound words. Even for verb-noun compound words, in which the verb stem would be the target, the following reading responses were made.

Ziehmutter (foster mother) Mutter...ziehen (mother...to pull)

Schießpulver (gun powder) schießen.. pulver (to shoot. . powder)

Meßbecher (measuring cup) messen. Glas (to measure.glass)

Sprechangst (stage fright) Angst..sprechen (fright. . to speak)

Kehrbesen (broom)

Klappbett (camp bed)

kehren Besen (to swipe broom)

Bett . . zusammenklappen (bed . . to fold together)

These examples may serve to summarize that (1) affix deletion is not the rule and (2) affix substitution was not arbitrary in H.J.'s paralexias to morphologically complex graphemic stimuli.

\section{Morphological Errors and Split Morphology}

An alternative position concerning the lexical representation of morphology was taken up by Anderson (1982) in his split morphology model. According to this view, there is a basic difference between syntax-generated inflectional processes and lexically constructed derivational forms. This position has been adopted in cognitive neuropsychology by Caramazza et al. (1988).

A possible difference between inflection and derivation was investigated using the reading data of H.J. She was given 155 morphologically complex words to read that have a transparent derivation. Of these words, 100 were 
derived from nouns (20 verbs, 80 adjectives) and 55 from verbs (40 nouns, 15 adjectives). Construction characteristics were the following.

Derivation of nouns $(n=100)$

$\mathrm{V}(\mathrm{n}=20)$ : nouns ending on $e r+n$. e.g., pfeffer-n (to pepper)

A $(\mathrm{n}=80)$ : noun $+i g(\mathrm{n}=35)$, e.g., witz-ig (funny)

noun + lich $(\mathrm{n}=30)$, e.g., ängst-lich (nervous)

noun + isch $(\mathrm{n}=15)$. e.g., neid-isch (jealous)

Derivations from verbs $(\mathrm{n}=55)$

$N(n=40)$ : verb stem + er, e.g., druck-er (printer)

A $(n=15)$ : verb stem + bar, e.g., trink-bar (drinkable)

They were compared with 20 simple monomorphemic nouns ending with -er (e.g., keller: cellar) and 60 monomorphemic adjectives with the following characteristics.

Highly frequent monosyllabic A $(\mathrm{n}=15)$, e.g., schön (pretty)

Highly frequent bisyllabic $A(n=15)$, e.g., bequem (easy)

Monomorphemic A ending with -er $(n=15)$, e.g., tapfer (courageous)

Monomorphemic A ending with $-i g(n=15)$, e.g., ledig (single)

For the underived words, no derivational errors were made. Along with correct reactions $(46 \%)$, mainly semantic paralexias $(29 \%)$ and zero reactions $(18 \%)$ were produced. In contrast, $55 \%$ of the stimuli derived from nouns were read with derivational errors, $73 \%$ of which consisted of only the noun stem, i.e.. the singular noun form. $24 \%$ of the plural noun form. The reactions to stimuli derived from verbs contained $38 \%$ derivational errors, $57 \%$ of which were infinitival verbs and $38 \%$ the third person singular present tense.

The pattern of the responses to derived forms is qualitatively not different from those to inflected forms. As responses to forms with a noun stem, a singular noun form is primarily produced. Here too it makes no difference whether the noun stem in the derived form is the same one as that in the underived one. Stimuli such as göttlich (divine) are read as Gott (god) as frequently as stimuli such as weiblich (female) are read as Weib (wife). The plural forms occurred mainly as reactions to derivations on -lich without umlaut stem (in 6 of 15 cases, e.g., kindlich $\rightarrow$ Kinder). We have as yet no systematic explanation for this finding. In the derived forms with the verb stem, the substituting form was primarily the infinitive, the second most frequent one a present tense form.

A direct comparison of derived agentive nouns on -er and inflected comparative adjectives on -er shows some quantitative difference in the patient's ability to produce a correct response (Table 3.4). This overall better performance for agentive nouns, however, may well be due to the different grammatical category of the complex target, nouns leading in general to correct reactions more frequent than adjectives.

In conclusion, it seems that none of the linguistic models of the lexicon is 
TABIE 3.4. Comparison of derived agentive nouns and inflected comparative adjectives on -er.

\begin{tabular}{lccccc}
\hline & \multicolumn{6}{c}{-er } \\
\cline { 2 - 5 } Words & Correct & 0 & Semantic & Visual & Morphological \\
\hline Comparative $(\mathrm{n}=32)$ & - & 1 & 3 & 1 & 27 \\
Agentive $(\mathrm{n}=3(0)$ & 8 & 6 & 2 & 3 & 11 \\
\hline
\end{tabular}

substantially supported by H.J.'s data-neither the lexical morphology model nor the model of split morphology. For the lexical morphology model, the difference between the processing of regular and irregular forms was not sufficiently outspoken: and with respect to the model of split morphology, no essential difference could be shown to exist between derivation and inflection. In addition, neither of these models is capable of offering an explanation for the systematic patterns evident in the reading errors of H.J.

If one keeps in mind, however, that the patient's lexical abilities are well preserved in other modalities, the psycholinguistic irrelevance of the internal structure of linguistic models comes as less of a surprise.

It need not necessarily be expected that the disturbances in processing graphemic stimuli would follow specific structural aspects of the internal lexicon, given that it is functioning well in other modalities. This case is more likely explained in terms of processing impairments that are specific to graphemic stimuli, whereby markedness hierarchies of the intact lexicon dictate specific compensatory strategies for this impairment.

\section{Morphological Errors and Information-Processing Models of Reading}

We now trace the specific contribution this case may provide to the currently existing psychologically oriented literature regarding the source of morphological errors in information-processing models. As Badecker and Caramazza (1986) have shown, there exist as yet no conclusive arguments that prove that errors considered "morphological" from an operational point of view show a functional difference compared to other errors, either semantic or visual. In other words, there is no conclusive evidence for an independent morphological error source, in contrast to semantic and visual errors, which are clearly differentiated from each other. For example, the English word thread has visual similarity but no semantic similarity to threat, and strong has only semantic but no visual relation to harder. In contrast, many so-called morphological errors have morphological as well as semantic and visual affinities to the target word (e.g., connection/disconnected).

In the following sections we will discuss some assumptions regarding the source of the morphological error that have appeared in the literature. 


\section{Morphological Errors to Affixed Words, Reflecting a Deficit of GPC}

Patterson (1982) proposed as a possible source of morphological errors that the lexical routes would process only stems. whereas affixes (and function words) would be much more dependent on mechanisms of graphemephoneme correspondence (GPC). A disturbance of the GPC route, which the standard theory assumes for deep and phonological dyslexia, would therefore lead to morphological errors as well. This assumption has become problematic since Caramazza et al. (1985) reported a patient who was incapable of reading nonwords (i.e., indicating that the GPC was disturbed) yet who did not produce morphological errors.

\section{Morphological Errors to Affixed Words, Reflecting a Disorder of the Presemantic Morphological Parser}

Job and Sartori (1984) argued that the morphological errors performed by their patient Leonardo were caused by a defect of a presemantic morphological parser. In their model of visual word processing, morphologically complex visual words are first parsed into their component morphemes, which then access the orthographic input lexicon in which root morphemes and affixes are distinguished. If there were a deficit in this presemantic parser, it would be predicted that when reading (1) only regularly inflected words should be affected, as irregular words do not undergo morphological parsing; and (2) morphological errors should occur only for truly prefixed words (e.g., ripreso in Italian, repayment in English) but not for pseudoprefixed words (e.g., ritardo in Italian, religion in English). Both predictions were met by the patient Leonardo. He read irregularly inflected words better than regular ones ( 15 of 33 correct versus 6 of 33), and he made only one morphological error among 15 pseudoprefixed words in contrast to 6 of 15 truly prefixed words.

Badecker and Caramazza (1987) offered an alternative solution for this dissociation that is not based on a functional-morphological disturbance. According to these authors, Job and Sartori's data are just as compatible if a visual source of disturbance is assumed as with the adopted morphological source of disorder. Badecker and Caramazza argued as follows: Pseudo-prefixed words such as religion have a cohort of visually similar items (e.g., legion, lion), which. however. are unrelated to each other in the lexical-semantic system. Words with real prefixes such as repayment usually have visual cohorts as well, e.g., payment, repay, pay, repaying, and paying, but these words also have a semantic relation to the target. As a consequence, it is much more likely that morphologically related forms are produced for words with real affixes (having visual-semantic cohorts) than for pseudoaffixed words (with only visual cohorts) even if the source of the disorder is of a visual nature. This effect is called "interface influence." Errors caused by the disturbance of a certain single component, 
such as the visual input system, may nonetheless reflect organizational traits of another component (such as the semantic component) which is closely connected to the first in a kind of interface relation.

The idea that the source of morphological errors may not be functionally morphological was further elaborated and given empirical support by Funnell (1987).

Morphological Errors to Affixed Words, Reflecting the Same Deficit Principles that Underlie Visual-Semantic Errors in Nonaffixed WORDS

Funnell (1987) took tissue with Job and Sartori's conclusions about the relation between morphological errors and a deficient presemantic parser. These conclusions rested crucially on the differential processing of affixed and pseudoaffixed words. However, as Funnell criticized, the item groups had not been matched for frequency or imageability of either the targets or the "stems" they contained. Frequency is known to play a role for visual recognition, imageability for semantic processing. Therefore if these variables are not controlled in affixed versus pseudoaffixed words, differences in performance may arise that are not related to the affix status, i.e., to morphology. Instead, they might reflect the same visual or semantic constraints that condition the reading of simple monomorphemic words and morphologically complex words alike.

Funnell investigated two patients with material controlled for morphological complexity, frequency, and imageability. One patient, C.J., was a phonological dyslexic and is not discussed here. The other patient, J.G., was a deep dyslexic patient, i.e., he could not read nonwords and made semantic, visual, and morphological paralexias when reading words. Moreover, Funnell demonstrated that his reading of words was strongly influenced by imageability. Highly imageable words were read well, whereas high frequency words with low imageability were rarely read correctly.

Patient J.G. was asked to read 32 pairs of suffixed and pseudosuffixed words matched for mean frequency and imageability. They were presented twice, so that each category contained 64 items, office-r/corn-er; hungr-y/bell-y. The patient made stem errors for words of both categories. Stem errors were defined as (1) reading of the stem/pseudostem only, e.g., mastery: master; irony: iron; (2) substituting another ending on the stem, e.g., speaker: speaking; irony: ironing.

Although the ratio of stem errors to pseudosuffixed words (13 of 64 : actually 7 of 32 words) was only half of the ratio of stem errors to suffixed words (30 of 64: actually 19 of 32 words), the results seemed to be clear counter-evidence to a morphological parsing explanation, which would predict no stem errors for pseudosuffixed words as opposed to suffixed ones.

A posthoc analysis seemed to indicate the effect of the relative image- 
ability of the target and stem for the occurrence of stem errors. This point was tested more stringently in another experiment in which 85 items represented three types of words: pseudosuffixed words (e.g., arm $+y$ ), embedded words (e.g.. grave $+l$ ), and truly affixed words (e.g.. sand $+y$ ). Imageability was varied as follows: highly imageable target and stem (army, gravel, sandy); target with low and stem with high imageability (mouser, wicker, cowl); target and stem with low imageability (nicety, tenure, realm).

The author's predictions were as follows: Words with high imageability on all counts should basically be read correctly. those with low target but high stem imageability should give rise to stem errors, and words low on all counts should lead to visual errors and omissions. These predictions were all borne out for J.G.; in other words, imageability was found to be the determining factor for successful reading of affixed words as well as stems (or pseudoaffixed and embedded words). Therefore morphological errors should be seen only as "apparently morphological" but not functionally so. They do not, Funnell concluded, reflect damage to a presemantic morphological parser; in fact. J.G. did not provide any evidence for existence of such a morphological parser.

To arrive at this conclusion, however, the author used a trick in her data analysis. Remember that the first experiment had shown that J.G. made (at least) double the amount of stem errors on suffixed words as he did on pseudosuffixed ones. Moreover, when the author did a post hoc analysis of the target-versus-stem imageability effect, she found that, in contrast to pseudosuffixed words, the patient made few correct responses to suffixed words with a highly imageable target but a low imageable stem (actually 4 of 7 items times two presentations), and quite a few stem errors occurred in these cases (in fact, 3 of 7 items). Funnell argued that they were not morphological errors but semantic errors; "Since J.G. makes a considerable number of semantic errors when reading unaffixed words. he is likely to make semantic errors when reading affixed words. If such errors share a common root morpheme with the target word, these errors will be indistinguishable from morphological (or stem) errors" (Funnell. 1987, p. 516).

The author used the results of another experiment to decide that those stem errors are in fact semantic. When asked to point to the name of the person when given two morphologically related word cards such as "typist." "typing," J.G. performed at chance. "J.G."s problem in comprehending suffixed words could be explained as a partial failure to access the meanings of affixes. Since affixes are relatively low in imageability, this failure fits with J.G.'s failure to access the meanings of other word types of low imageability" (Funnell, 1987). Consequently, Funnell gave those suffixed words with a high imageability rating for both stem and target a different treatment in the second reading experiment. which was controlled for imageability. She analyzed them together with the non- 
TABI. 3.5. Experiment 2: number of response types (correct, stem errors, visual errors, and omissions) produced by J.G. to 85 words grouped according to predictions based on imageability levels of the target word and stem.

\begin{tabular}{|c|c|c|c|c|c|c|}
\hline \multirow[b]{2}{*}{$\begin{array}{l}\text { Target/stem } \\
\text { imageability }\end{array}$} & \multirow[b]{2}{*}{$\begin{array}{c}\text { Word } \\
\text { set }\end{array}$} & \multirow[b]{2}{*}{$\begin{array}{l}\text { Response } \\
\text { predicted }\end{array}$} & \multicolumn{4}{|c|}{ Reading response } \\
\hline & & & $\begin{array}{l}\text { No. of } \\
\text { words }\end{array}$ & Correct & $\begin{array}{l}\text { Stem } \\
\text { errors }\end{array}$ & $\begin{array}{l}\text { Visual errors } \\
\text { and omissions }\end{array}$ \\
\hline High/high" & $\mathrm{C}$ & Correct & 24 & $19(+1)$ & 2 & 2 \\
\hline Low/high $^{\mathrm{b}}$ & $\mathrm{D}$ & Stem errors & $34^{\circ}$ & $6(+2)$ & $17(+1)$ & 7 \\
\hline Low/low & $\mathrm{E}$ & $\begin{array}{l}\text { Visual errors } \\
\text { and omissions }\end{array}$ & $27^{\mathrm{d}}$ & $0(+2)$ & 4 & 19 \\
\hline
\end{tabular}

"With the exception of suffixed words.

h Including high/high suffixed words.

One unclassified error not included in the analysis.

"Two unclassified errors not included in the analysis

Vote: Semantic errors, counted as correct responses or stem errors, are given separately in parentheses.

(C) From Funnell (1987). With permission from Lawrence Erlbaum Assoc. Ltd.

suffixed items which have a low imageable target and a highly imageable stem! The results for J.G. analyzed in this (rather unorthodox) way are shown in Table 3.5. The predicted responses and responses obtained overall were significantly related, $\chi^{2}=50.21$, df $=4, p<.001$.

However, the prediction that imageability, not morphology, is the principal variable is borne out only if one accepts, with the author, the theoretical bias that morphologically complex words of high imageability are actually low-imageable for the patient, i.e., if one assumes that the cause of the stem errors to suffixed words is semantic rather than morphological-but this point is exactly what the author wanted to prove. She stated: "With one small exception, predicted patterns of performance in this experiment were not based upon distinctions between suffixed, pseudo-suffixed, and embedded words.... The single exception to this recognized the fact that J.G. is likely to make stem errors to suffixed words even when the target word is higher in imageability than the stem" (Funnell, 1987, p. 521). If one reanalyzes the data without this strong assumption in a theory-neutral way, the results no longer speak as convincingly against a morphological parser account and in favor of a unified imageability account.

We took the suffixed words with a highly imageable target and stem out of the category with low imageable targets/high imageable stems (set D) and put them back in set $\mathrm{C}$, so far containing pseudosuffixed and embedded words with overall high imageability. Set E contained words with overall low imageability. The results for J.G. were then as shown in Table 3.6.

The prediction that Hihi would be read correctly was no longer fulfilled. The maximum probability criterion was now .82 (for $\mathrm{P}_{\mathrm{c}}=.90 / .95$, at least 30 of 38 or 33 of 38 items should have been read correctly). Furthermore, 
TABLE 3.6. Reanalysis of experiment 2 of Funnell (1987).

\begin{tabular}{lccccc}
\hline & & \multicolumn{3}{c}{ Reading responses } \\
\cline { 4 - 6 } $\begin{array}{l}\text { Target/stem } \\
\text { imageability }\end{array}$ & $\begin{array}{c}\text { Funnell's } \\
\text { predicted response }\end{array}$ & No. of words & Correct & $\begin{array}{c}\text { Stem } \\
\text { errors }\end{array}$ & $\begin{array}{c}\text { Visual errors/ } \\
\text { omissions }\end{array}$ \\
\hline Hihi & Correct & 38 & $23(+3)$ & 10 & 2 \\
Lihi & Stem errors & 20 & $2(+1)$ & $10(+1)$ & 6 \\
Lili & $\begin{array}{l}\text { Visual errors } \\
\text { + omissions }\end{array}$ & 27 & $-(+2)$ & 5 & 20 \\
& & & & &
\end{tabular}

"Hihi = high imageability of target and stem. Lihi = low imageability of target, high imageability of stem. Lili = low imageability of target and stem.

using Fischer's exact $2 \times 2$ table test (PC computer program StatXact 1989), there was no longer any significant difference between the occurrence of stem errors to Hihi and to Lihi items ( $p=.1943$, one-sided, n.s.). The number of stem errors in the Hihi category was indeed largely due to the reinclusion of truly affixed words. Again using Fischer's $2 \times 2$ exact table test, affixed words triggered significantly more $(p=.0019$, one-sided $)$ stem errors ( 8 of 14 ) than did nonaffixed words (2 of 24$)$. Although it was no longer the case for the Lihi category, it must be remarked that there were only five truly affixed words (probably with one misclassification: purser/purse) of which four triggered a stem error. in contrast to 15 nonor pseudoaffixed words (with the likely misclassification of "signify") with six stem errors. The category Lili was a mixed one, including many function words in both stem and target groups (12 of 27), which are known to provoke zero reactions in deep dyslexic patients.

To test Funnell's prediction with our own patient, H.J., we used the more stringent condition of her test; i.e., the target was of low imageability and the stem of high imageability in pseudoaffixed or embedded words. Funnell here predicted the occurrence of "stem errors." By way of comparison, we gave our patient 40 "stems" to read in isolation, and 12 of them were used in pseudosuffixed words, 28 in embedded words. Examples are shown in Table 3.7. The low-imageable items were given together in a first presentation so as to not bias "stem reading"; the high imageable "stems" were presented later in the same session.

Of the low-imageable items, 15 of 40 were read correctly. In only 2 of 40 cases did the "stem" occur as the only response. In another six cases, the

TABLE 3.7. Stem errors.

\begin{tabular}{|c|c|c|}
\hline $\begin{array}{l}\text { High-imageable } \\
\operatorname{stem}(n=4())\end{array}$ & $\begin{array}{l}\text { Low-imageable pseudosuffix } \\
(\mathrm{n}=12)\end{array}$ & $\begin{array}{l}\text { Low-imigcable } \\
\text { embedded }(\mathrm{n}=28)\end{array}$ \\
\hline Beton (concrete) & Betonung (cmphasis) & \\
\hline Fass (barrel) & Fassung (mounting, composure) & \\
\hline Ei (egg) & & Eile (haste) \\
\hline Klo (toilet) & & Klobig (clumsy) \\
\hline
\end{tabular}


highly imageable stem or a semantic paraphase thereof was part of the naming reaction, but additional responses or comments showed that $\mathrm{H} . J$. did not consider this reading response to be adequate.

auto-mat (car/automat)

Auto... maschine irgendwas (car... machine something)

strauch-eln (bush/stumble) Strauch... laufen irgendwas (bush ... run something)

ehe-r (marriage/sooner) Ehe. .hat nichts mit Ehe zu tun (marriage. has nothing to do with marriage)

The remaining reactions were as follows.

1. Semantic paralexia to the whole item $(n=7)$, e.g. Komma-ndo (comma/command, detachment): Soldaten irgendwas. Befehl (soldiers something, command)

2. Morphological paralexia to the whole item $(n=5)$, e.g., hand-el (hand/ trade): handeln (to trade)

3. Zero-reaction $(n=4)$

4. Non-classifiable $(\mathrm{n}=1)$

Of the 40 high-imageable "stems" presented in isolation, 36 were spontaneously read correctly; there was one zero reaction, one paraphrase, and one semantic paralexia; and in one case the "complex" item was remembered and transferred onto the single one.

This task shows that H.J., like J.G., had a clear imageary effect in reading, but this fact does not override morphological parsing. Words that are pseudocomplex rarely lead to "pseudomorphological errors," which strongly indicates that the morphological errors H.J. made when reading morphologically complex words should not be interpreted as simple semantic errors. The exact nature of the morphological error in H.J., as in J.G., still needs to be explained.

\section{The Nature of the Morphological Error in H.J.}

To appreciate the nature of H.J. 's morphological errors, we compared her performance to the different proposals in the literature.

\section{H.J. 's Morphological ERrors: do not Reflect the GPC Deficit}

The fact that H.J. processed at least some affixes semantically testifies to their lexical status (see above for a report on the diminutives -chen and -lein and the negative un-). Moreover, an analysis of the semantic paralexias to derived adjectives $(n=58)$ demonstrates that syntactic aspects of suffixation were computed by H.J. Leaving aside the multiword paraphrases $(21 \%), 60 \%$ of the semantic paralexias to derived adjectives were 
also adjectives, indicating that the syntactic category of the suffix had been recognized by the cognitive system. Examples are the following.

$\begin{array}{ll}\text { herrlich (delicious) } & \text { froh (happy) } \\ \text { niedrig (low) } & \text { klein (small) } \\ \text { morgig (of tomorrow) } & \text { früh (early) } \\ \text { herrisch (domineering) } & \text { stark (strong) }\end{array}$

These data defeat a purely prelexical account of affixation.

\section{H.J.'s Morphological Errors: do Not Reflect a Parsing Problem}

A disorder in the presemantic morphological parser would predict that only regular, not irregular, affixation would be impaired. We showed earlier in the chapter that there was no significant different between these parameters in H.J.'s data. Moreover, the data against GPC also speak against an affix-stripping assumption, as (some) affixes obviously do contact the cognitive system.

\section{H.J. 's Morphological Errors Reflect a Semantic Variable that AfFects both AffiXed and Nonaffixed Words}

We disagree with Funnell's conclusion that cases such as ours do not provide evidence for morphological parsing in reading. Not only can one see the patient tracing the morphology with her finger, but morphologically complex and pseudo-complex words are treated differently. In the former case, they generally trigger a morphological default system of verbal infinitives, singular nouns, and positive forms of the adjective. The default system even works if the derivation or inflection uses a different stem than the citation form (e.g., göttlich (divine), response: Gott (god), kürzer (shorter), response: kurz (short); tückisch (whimsical), response: Tücke (whim). Reducing morphological errors to the presence of visual-semantic cohorts would ignore this obvious system.

However, we do agree with Funnell that these morphological errors do not result from damage to the morphological parser but, rather, from variables affecting the reading of affixed and nonaffixed words alike, i.e., semantic factors.

If we adopt such a unitary explanation in terms of referential semantics, the following observations can be covered.

1. A strong effect of imageability could be seen for reading morphologically simple words in the partial replication of Funnell reported above.

2. Proper names cannot be read by H.J., as they do not have enough intensional structure (descriptive force) to invoke the semantic system, which is required for phonological realization.

3. Those morphologically complex forms that contain an affix with hardly any referential semantics can be realized only phonologically because the linguistic system offers morphologically unmarked forms as substitutes. 


\section{Conclusion}

Marshall and Newcombe (1973) introduced three tasks for future research: (1) formalization of a word recognition and word retrieval model; (2) extension of the interpretive value of such models by considering languages with other writing systems, e.g., syllabic and ideographic ones; and (3) investigation of the relation between dyslexias and dysgraphias. Fifteen years of research on disorders of written language within this paradigm have led to favorable results. In no other area of neuropsychology has the interaction between theory and pathology been so intensive. For each point of the above program, several books have meanwhile been published.

The models available to date have the disadvantage that the internal architecture of the single components have remained largely undetermined. With the elaboration of such models for specific languages, some questions therefore have remained in principle unanswerable. One example is the representation and processing of morphologically complex forms and function words.

With respect to the morphological errors $H . J$. made in her reading performance, we could show that they were not caused by either semantic or morpholexical defects. The error pattern that emerged was interpreted as a lexical compensation process that made use of markedness principles. We purposely prefer to remain somewhat vague as to exactly what is actually compensated because our knowledge about the internal structure of the orthographic input lexicon is still too unspecific. The existing proposals on these structures clearly cannot explain our data. On the one hand, there is the "addressed morphology model," in which the processing of morphologically complex lexemes involves activation of the word as a single, whole unit from the orthographic lexicon. On the other hand, a "morphological parsing model" has been proposed that assumes a complex word is first decomposed into roots and affixes and that processing then proceeds only according to roots (see Butterworth, 1983, for a comparison of these two views).

Within the context of the first model, it would be difficult to explain H.J.'s reactions-in particular, why there is such a stable pattern of morphological paralexias: One would expect variability in the responses. According to the second, parsing model, the semantic paralexias the patient makes would have to belong to the syntactic category of the word's root only and not to the syntactic category of the entire lexeme. H.J. processes at least the syntactic information of the affix, and wherever possible its semantic contribution as well.

We can hardly claim to have found a general solution for the problems of deep dyslexia or, more specifically, for morphological errors. However, we do believe that we can plausibly infer the symptoms of H.J.'s reading from the assumed disorders. In particular, we have demonstrated in this case study how morphological errors may arise by graphemic presentation 
without any defect of the visual input system. with a well functioning morphological parser, and with retained morphology in the internal lexicon and the output lexicon. Morphological errors can arise at the interface between the graphemic input lexicon and the semantic system.

The unitary explanation we propose is that referential semantic contents determine what can be read, for content words, function words, and affixes. Our data are irreconcilable with theories starting from a general problem with "little words," as H.J. does not simply ignore function words and even bound morphemes. Our results are consistent, however, with the general observation that deep dyslexics can identify concrete words more easily than abstract ones, and that a word class effect can be recognized when reading.

\section{Summary}

The nature of the morphological error in word reading based on an analysis of the responses of a German patient with "deep dyslexia" has been discussed. The case provides compelling evidence for morphological decomposition in visual word recognition. At the same time, it shows that the occurrence of morphological paralexias does not necessarily presuppose an impairment of the process involved in morphological decomposition during lexical access. The source of such errors may lie in particular properties of the reading system that affect affixed and unaffixed words alike. i.e.. low referential semantic content. The pattern of the morphological errors in this case and their dissociation from nongraphemic morphological processing does not reflect a morphological deficit but, rather, the properties of spared morphological representations that provide markedness features used for coping with the deficit of processing morphologically complex graphemic stimuli.

Acknowledgment. This chapter is the result of research supported by the DFG (German National Science Foundation) and by the Max Planck Institute for Psycholinguistics. We would like to thank Klaus Willmes for his help with the statistical analysis.

\section{References}

Anderson, S.R. (1982). Where's morphology? Linguistic Inquiry, 13, 571-613.

Badecker, W. \& Caramazza. A. (1987). The analysis of morphological errors in a case of acquired dyslexia. Brain and Language, 32, 278-305.

Butterworth. B. (1983). Lexical representation. In B. Butterworth (ed.), Language Production (Vol. 2). London: Academic Press.

Caramazza. A. (1986). Reading and lexical processing mechanisms. Reports of the Cognitive Neuropsychology Laboratory. Baltimore: The Johns Hopkins University. 
Caramazza, A., Laudanna, A., \& Romani. C. (1988). Lexical access and inflectional morphology. Cognition, 28, 297-332.

Caramazza, A., Miceli, G., Silveri, M.C., \& Laudanna, A. (1985). Reading mechanisms and the organisation of the lexicon: evidence from acquired dyslexia. Cognitive Neturopsychology, 2, 81-114.

De Bleser, R., \& Bayer, J. (1986). German word formation and aphasia. The Linguistic Review, 5, 1-40.

Funnell, E. (1987). Morphological errors in acquired dyslexia: a case of mistaken identity. The Quarterly Journal of Experimental Psychology, 39A, 497-5.39.

Futter, C.. \& Bub, D. (1986). A level-ordered theory of morphological paralexias. Presented at the Academy of Aphasia. Nashville, October 1986.

Job, R., \& Sartori. G. (1982). Prelexical decomposition: evidence from acquired dyslexia. British Journal of Psychology, 74, 159-180.

Job, R., \& Sartori, G. (1984). Morphological decomposition: evidence from crossed phonological dyslexia. The Quarterly Journal of Experimental Psychology, 36, 435-458.

Kiparsky, P. (1982). From cyclic phonology to lexical-phonology. In H. van der Hulst \& N. Smith (eds.), The Structure of Phonological Representaion. Part I. Dordrecht: Foris.

Köpcke, K.-M. (1987). Die Beherrschung der deutschen Pluralmorphologie. Linguistische Berichte, 107, 23-44.

Marshall. J.C. \& Newcombe, F. (1973). Patterns of paralexia: a psycholinguistic approach. Journal of Psycholinguistic Research, 2, 175-199.

Patterson. K. (1980). Derivational errors, In M. Coltheart, K. Patterson. \& J.C. Marshall (eds.), Deep Dyslexia. London: Routledge and Kegan Paul.

Patterson. K.E. (1981). Neuropsychological approaches to the study of reading. British Journal of Psychology. 72. 151-174.

Patterson. K.E. (1982). The relation between reading and phonological coding: further neuropsychological observations. In A.W. Ellis (ed.), Normality and Pathology in Cognitive Functioning. London: Acadenic Press.

StatXact (1989). Statistical Software for Exact Nonparametric Inference. New York: Cytel Software Corporation. 